\title{
Clinical and histological features of delta infection in chronic hepatitis B virus carriers
}

\author{
ASF LOK, I LINDSAY, PJ SCHEUER, HC THOMAS \\ From the Departments of Medicine and Histopathology, Royal Free Hospital and School of Medicine, \\ London NW3
}

SUMMARY One hundred and six consecutive chronic hepatitis B virus (HBV) carriers were studied for the prevalence of delta markers in serum and tissue, and the clinical and histological features of those with and without delta infection were compared. Twenty (18.9\%) patients were positive for anti-delta in serum or delta antigen in the liver or both. They presented at a younger age (30.3v 38 years). All of them were symptomatic at the time of biopsy, in contrast to $35 \%$ of patients without delta infection who were not symptomatic. Those with delta infection had higher serum transaminase values and showed more severe liver damage on biopsy: chronic active hepatitis in $45 \%$ and cirrhosis in $55 \%$. There was more pronounced disease activity both within the parenchyma and in the portal and periportal zones. The histological diagnosis of the 86 patients without delta infection included minimal disease $(10 \%)$, chronic persistent hepatitis (9\%), chronic active hepatitis $(62 \%)$, and cirrhosis $(19 \%)$. Delta infection in chronic HBV carriers is associated with a more active and progressive liver disease.

The delta agent is a defective hepatitis virus with a putative ribonucleic acid genome.' It requires the presence of hepatitis B virus (HBV) for its replication. $^{2}$ It was first described in 1977 in an Italian chronic HBV carrier. ${ }^{3}$ Since then, epidemiological studies have shown that it occurs world wide, but it is most common in Mediterranean countries. ${ }^{4}$ In northern Europe and America the prevalence of delta antibody in the serum or of delta antigen in mainly to drug addicts and multiply transfused sub-

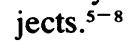

The diagnosis of coexistent delta infection in chronic HBV carriers depends on the detection of delta antibody in the serum or of delta antigen in the liver. Delta antigen in serum is detectable in only a minority of patients during the early stages of infection. ${ }^{2}$ The presence of delta infection in a chronic HBV carrier usually results in a more severe and rapidly progressive type of liver disease. ${ }^{3679}$ Certain histological features have been reported to be associated with delta infection, ${ }^{9}$ but these are too non-specific to be of any great diagnostic use.

To determine the effect of delta infection on the course and severity of the liver disease in chronic HBV carriers we conducted a retrospective study to analyse the prevalence of delta markers and to com-

Accepted for publication 5 February 1985 pare the clinical and histological features of those with and without delta infection.

\section{Material and methods}

PATIENTS

One hundred and six consecutive chronic HBV carriers referred to the Department of Medicine at the Royal Free Hospital were studied. All of them had had liver biopsies performed between January 1980 and June 1982. The patients had been hepatitis B surface antigen (HBsAg) positive for at least six months. Patients who had received antiviral or immunosuppressive treatment during the three months before biopsy and those in whom an alternative cause for the liver disease was suspected were excluded.

\section{SEROLOGY}

HBsAg, hepatitis $\mathrm{Be}$ antigen ( $\mathrm{HBeAg}$ ), and anti$\mathrm{HBe}$ were tested by radioimunoassay (Abbott Laboratories). Serum samples taken at the time of liver biospy were stored at $-20^{\circ} \mathrm{C}$, coded, and sent for blind analysis of antidelta by a solid phase blocking radioimmunoassay (kindly performed by $\mathrm{Dr} M$ Rizzetto, Department of Medicine, Turin). HBVDNA was measured by dot/blot hybridisation. ${ }^{10}$ 
INTRAHEPATIC DELTA ANTIGEN

This was detected by immunoperoxidase staining. Routine $4 \mu \mathrm{m}$ sections were dewaxed, taken to alcohol, and treated for 30 min with $1 \%$ hydrogen peroxide solution in methanol to block endogenous peroxidase activity. Slides were trypsinised for $8 \mathrm{~min}$ at $37^{\circ} \mathrm{C}$ using a $0.1 \%$ trypsin (Sigma Type 11 ) in $0.1 \%$ calcium chloride solution at $\mathrm{pH} 7 \cdot 4$. After washing, they were incubated with a peroxidase conjugated human antidelta IgG (kindly provided by Dr M Rizzetto), diluted to 1/70 in phosphate buffered saline (PBS). After washing in PBS the peroxidase reaction product was demonstrated using $3^{\prime} 3^{\prime}$ diaminobenzidine (BHD) after the method of Graham and Karnovsky." Slides were washed, counterstained with Carrazzi's haematoxylin, dehydrated, and mounted.

\section{HISTOLOGICAL DIAGNOSIS}

Diagnoses were made according to generally accepted criteria, ${ }^{12}$ and patients were classified as having minimal disease, chronic persistent hepatitis, chronic active hepatitis with or without cirrhosis, or inactive cirrhosis. The activity of the liver disease was assessed by a pathologist (IL), who was unaware of the serological status, and an activity index (0-4) was recorded for both the portal zones and the parenchyma. In portal zones a score of 1 denoted inflammatory infiltration without piecemeal necrosis (chronic persistent hepatitis), while scores of 2, 3, and 4 denoted mild, moderate, and severe piecemeal necrosis (chronic active hepatitis) respectively; parenchymal score 1 denoted inflammation without necrosis. Scores 2, 3, and 4 were used for varying degrees of hepatocellular necrosis and inflammation. Scores of 0 were allotted when inflammation and necrosis were absent.

\section{STATISTICAL ANALYSIS}

Student's $t$ test was used to compare the mean ages, serum transaminase values, and activity indices of the patients with and without delta infection.
Table 1 Characteristics of chronic hepatitis $B$ virus carriers with and without delta infection

\begin{tabular}{lll}
\hline & Delta positive & Delta negative \\
\hline No of patients & 20 & 86 \\
HBeAg positive & 5 & 50 \\
Anti-HBe positive & 15 & 36 \\
Sex ratio (M:F) & $18: 2$ & $81: 5$ \\
Age (yr) (range) & $30 \cdot 3(18-51)$ & $38(14-62)$ \\
\hline
\end{tabular}

$\mathrm{HBeAg}=$ hepatitis $\mathrm{B}$ e antigen.

\section{Results}

Twenty of the 106 patients with $\mathrm{HBV}$ induced chronic liver disease (18.9\%) had evidence of delta infection as shown by high titre antidelta in the serum or delta antigen in the hepatocyte nuclei or both. Five of these patients were $\mathrm{HBeAg}$ positive and 15 were anti-HBe positive. Fifty of the 86 patients without delta infection were $\mathrm{HBeAg}$ positive and the remaining 36 were anti-HBe positive. There was a preponderance of men in the patients with delta infection and in those without (male:female 18:2 and 81:5, respectively) (Table 1). The patients with delta infection presented at a younger age. Their mean age at the time of biopsy was 30.3 years (18-57), while the mean age of those without delta infection was 38 years $(14-62)$ ( $p<$ 0.05 ). Nine of 15 delta positive, anti-HBe positive carriers were tested for HBV-DNA and all were negative.

\section{ETHNIC ORIGINS AND POSSIBLE MODES OF TRANSMISSION}

Table 2 shows the prevalence of delta infection in the various clinical groups. All seven British patients were either parenteral drug abusers or haemophiliacs; four of the remaining 13 were drug addicts but none was haemophiliac. By comparison, there were six addicts and one haemophiliac among the 86 patients without delta infection. Delta markers were

Table 2 Prelavence of delta infection among the different ethnic groups and the possible modes of transmission of delta agent

\begin{tabular}{lccc}
\hline Ethnic origin & No studied & $\begin{array}{c}\text { No positive for delta } \\
\text { infection (\%) }\end{array}$ & Addicts \\
\hline British & 49 & $7(14 \cdot 3)$ & 6 \\
Mediterranean & 29 & $6(20 \cdot 1)$ & 1 \\
Middle Eastern & 13 & $5(38 \cdot 5)$ & 0 \\
Oriental & 9 & $0(0)$ & 1 \\
African & 4 & $1(25)$ & 0 \\
Central American & 2 & $1(50)$ & 0 \\
Total & & 20 of $106(18 \cdot 9 \%)$ & 0 \\
\hline
\end{tabular}


Table 3 Clinical presentation of chronic hepatitis $B$ virus carriers with and without delta infection

\begin{tabular}{lcc}
\hline Clinical presentation & $\begin{array}{l}\text { Delta positive } \\
(n=20)\end{array}$ & $\begin{array}{l}\text { Delta negative } \\
(n=86)\end{array}$ \\
\hline History of acute hepatitis & 14 & 26 \\
At biopsy: & 0 & \\
$\quad$ Asymptomatic & 10 & 56 \\
Lethargy & 0 & 15 \\
Arthralgia & 2 & 2 \\
Jaundice & 3 & 4 \\
Right upper quadrant pain & 2 & 4 \\
Portal hypertension & 3 & 5 \\
Hepatic failure & 0 \\
\hline
\end{tabular}

not detected in any of the 26 homosexuals studied, 23 of whom were British.

CLINICAL PRESENTATION (Table 3)

A history of acute hepatitis was elicited in $14(70 \%)$ of 20 patients with delta infection but in only 26 $(30 \%)$ of 86 patients without coexistent delta infection. All the patients with delta infection were symptomatic at the time of biopsy. Five of them presented with late complications of chronic liver disease: portal hypertension in two and hepatic failure in three. In contrast, $65 \%(56 / 86)$ of patients without delta infection were asymptomatic. The remaining patients had mild symptoms. Only five presented with portal hypertension, and none was in hepatic failure at the time of biopsy.

\section{SERUM TRANSAMINASE VALUES}

The mean serum transaminase (AST) values at the time of biopsy were significantly higher $(p<0.01)$ in those with delta infection (average $121 \mathrm{IU} / \mathrm{l}$, range 56-280) than in those without (average 60, range 20-210).

\section{HISTOLOGICAL CHANGES (Table 4)}

Those with delta infection had more severe liver disease on biopsy. Nine (45\%) had chronic active hepatitis, mainly moderate or severe in activity, and the remaining $11(55 \%)$ had active cirrhosis. The histological diagnoses of the remaining 86 patients

Table 4 Histological diagnoses in relation to the presence or absence of delta infection

\begin{tabular}{llc}
\hline Histological diagnosis & $\begin{array}{l}\text { Delta positive } \\
(n=20)\end{array}$ & $\begin{array}{l}\text { Delta negative } \\
(n=86)\end{array}$ \\
\hline Minimal disease & 0 & $9(10 \%)$ \\
Chronic persistent hepatitis & 0 & $8(9 \%)$ \\
Mild chronic active hepatitis & 1 & 38 \\
Moderate chronic active hepatitis & $69(45 \%)$ & $1453(62 \%)$ \\
Severe chronic active hepatitis & 2 & 1 \\
Inactive cirrhosis & $011(55 \%)$ & $1016(19 \%)$ \\
Active cirrhosis & 1111 & 6 \\
\hline
\end{tabular}

were more varied: $17(19 \%)$ had mild liver disease and only $16(19 \%)$ had cirrhosis, mostly inactive. The mean activity indices in the patients with delta infection were significantly higher $(\mathrm{p}<0.01)$ : the difference in the parenchymal activity $(2.6 v 1.14)$ was more striking than the difference in portal and periportal inflammation and necrosis $(2.65 v 1.48)$.

\section{Discussion}

Coexistent delta infection was present in $18.9 \%$ of 106 patients with HBV induced chronic liver disease. In British patients the prevalence was $14.3 \%$, which accords with the rates that have previously been reported, ${ }^{67}$ and was confined to the addicts and haemophiliacs. We did not find any delta markers in 26 homosexual carriers, 23 of whom were British. It has been suggested that there is little overlap between the addict and homosexual populations, based on differences in the HBsAg subtypes. ${ }^{7813}$ An alternative explanation is that the inoculum transmitted sexually may be smaller than that transferred by the parenteral route, and perhaps insufficient to cause delta infection. In the chimpanzee, a $10^{-8}$ dilution of serum containing $\mathrm{HBV}$ and delta agent results in loss of delta but not HBV infectivity. ${ }^{2}$

Delta infection was found in $20-50 \%$ of patients from other parts of the world. In most of these the mode of transmission was not apparent. ${ }^{4}$ Studies in Italy have shown familial clustering of delta infection $^{13}$ and it is possible that the delta agent may spread through other routes via close contacts in endemic areas.

The patients with delta infection presented at a significantly younger age. It is possible that our patients acquired $\mathrm{HBV}$ infection at comparable ages, but that coexistent delta infection produced a more severe disease and therefore earlier presentation. HBV infection may cause either a clinically obvious or a subclinical hepatitis, and our patients without delta infection may have remained undetected for many years. Indeed, at the time of biopsy all our patients with delta infection were symptomatic, whereas most of those without delta infection were symptom free. A higher proportion of our patients with delta infection had histories of acute hepatitis, some having had more than one episode. This could represent an acute hepatitis B infection or acute hepatitis due to superinfection with delta agent in a chronic HBV carrier.

The patients with delta infection also had higher serum transaminase values and more severe liver disease on biopsy, with more striking activity in the parenchyma and to a lesser extent in the portal zones. The continuing parenchymal activity was surprising as the majority, 15 , of our patients with delta 
infection were anti-HBe positive and therefore had low or undetectable rates of $\mathrm{HBV}$ replication. In certain geographical regions, such as the Mediterranean countries, despite a high spontaneous seroconversion rate from $\mathrm{HBeAg}$ to anti-HBe, up to $40 \%$ of patients who are anti-HBe positive may still have active viral replication with HBV-DNA in serum or hepatitis $B$ core antigen in the liver. ${ }^{10} 15$ This may account for the persistently active liver disease in such patients. In our 15 patients with delta infection who were anti-HBe positive, however, all nine tested for serum HBV-DNA were negative, and only one of the six tested for hepatitis B core antigen in the liver was positive. Thus the increased activity of the liver disease in these patients could not be due to persistent HBV replication producing a continuous, immune mediated lysis of infected hepatocytes. Half of our patients with delta infection were drug addicts, and it is possible that some of them may also have had non- $\mathrm{A}$, non-B hepatitis contributing to a more severe liver disease. In Italy, however, delta infection is endemic among HBV carriers and is not confined to addicts and haemophiliacs, but a more severe liver disease is still found.'

Liver disease in HBV infection is believed to be the result of immunological attack on hepatocytes displaying viral antigens. ${ }^{16}$ It has been suggested that delta is a cytopathic agent, and that there may be synergistic liver damage in chronic HBV carriers with coexistent delta infection. ${ }^{9}$ This may not only potentiate existing liver damage but may also hasten the rate of progression. In our study five of the 20 patients with delta infection presented with late complications of chronic liver disease-namely, portal hypertension and hepatic failure. Over half, $55 \%$, already had established cirrhosis on biopsy.

The discovery of the delta agent helps to explain why in certain chronic HBV carriers the liver disease may remain active and progressive despite low levels of $\mathrm{HBV}$ replication; delta markers in chronic $\mathrm{HBV}$ carriers indicate a more ominous prognosis. Clinical studies have shown that this severe and progressive liver disease is unresponsive to immunosuppressive therapy. ${ }^{9}$ The role of antiviral treatment has yet to be evaluated.

ASFL is supported by the University of Hong Kong. IL is a Wellcome Research Fellow.

\section{References}

' Rizzetto M, Hoyer B, Canese MG, Shih JWD, Purcell RH, Gerin JL. Delta agent: the association of delta antigen with hepatitis B surface antigen and RNA in serum of delta-infected chimpanzees. Proc Natl Acad Sci USA 1980;77:6124-8.

${ }^{2}$ Rizzetto M, Canese MG, Gerin JL, London WT, Sly LD, Purcell $\mathrm{RH}$. Transmission of hepatitis B virus-associated delta antigen to chimpanzees. J Infect Dis 1980;141:590-62.

${ }^{3}$ Rizzetto M, Canese MG, Arico S, et al. Immunofluorescence detection of a new antigen-antibody system (delta/anti-delta) associated with hepatitis $B$ virus in liver and serum of $\mathrm{HBsAg}$ carriers. Gut 1977; 18:997-1003.

${ }^{4}$ Rizzetto M, Purcell RH, Gerin JL. Epidemiology of HBVassociated delta agent: geographical distribution of anti-delta and prevalence in polytransfused $\mathrm{HBsAg}$ carriers. Lancet 1980;i:1215-8.

${ }^{5}$ Raimondo G, Smedile A, Gallo L, Balbo A, Ponzetto A, Rizzetto M. Multicentre study of prevalence of HBV-associated delta infection and liver disease in drug addicts. Lancet 1982;i:249-51.

${ }^{\circ}$ Lok ASF, Farci P, Thomas HC. Epidemiology and clinical course of delta infection in Britain. In: Rizzetto M, Verme G, eds. infection and viral hepatitis. New York: Alan A Liss Inc.

${ }^{7}$ Weller IVD, Karayiannis P, Lok ASF, et al. The significance of delta infection in chronic hepatitis B viral infection in Great Britain. Gut 1983;24:1061-3.

${ }^{8}$ Hansson BG, Moestrup T, Widell A, Nordenfelt E. Infection with delta agent in Sweden: Introduction of a new hepatitis agent. J Infect Dis 1982;146:472-8.

' Rizzetto M, Verme G, Recchia S, et al. Chronic hepatitis in carriers of hepatitis B surface antigen, with intrahepatic expression of the delta antigen: an active and progressive disease unresponsive to immunosuppressive treatment. Ann Intern Med 1983;98:437-41.

${ }^{10}$ Weller IVD, Fowler MJF, Monjardino J, Karayiannis P, Thomas HC. The detection of HBV-DNA in serum by molecular hybridisation: a more sensitive method for detection of complete HBV particles. J Med Virol 1980;9:273-80.

"Graham RC, Karnovsky MJ. The early stages of absorption of injection horseradish peroxidase in the proximal tubules of mouse kidney: ultrastructural cytochemistry by a new technique. J Histochem Cytochem 1966;14:291-302.

${ }_{12}$ Scheuer PJ. Liver biopsy interpretation. 3rd ed. London: Bailliere Tindall, 1980.

${ }^{13}$ Tedder RS, Briggs H, Howell DR. UK prevalence of delta infection. Lancet 1982; ii:764-5.

${ }^{14}$ Caporaso N, Colforti M, DelVecchio Blanco C, Farci P, Servillo F, Suozzo R. Familial clustering of delta infection and chronic hepatitis. Ital J Gastroenterol 1983;15:61-74.

15 Lieberman HM, LaBrecque DR, Kew MC, Hadziyannis SJ, Shafritz DH. Detection of hepatitis B virus DNA directly in human serum by a simplified molecular hybridization test: comparison to $\mathrm{HBeAg} /$ anti- $\mathrm{HBe}$ status in $\mathrm{HBsAg}$ carriers. Hepatology 1983;3:285-91.

${ }^{16}$ Dudley FJ, Fox RA, Sherlock S. Cellular immunity and hepatitis-associated, Australia antigen liver disease. Lancet 1972;i:723-6.

${ }^{17}$ Eddleston ALWF, Williams R. Inadequate antibody response to HG Ag or suppressor $\mathrm{T}$ cell defect in development of active chronic hepatitis. Lancet 1974;ii:1543-5.

Requests for reprints to: Dr HC Thomas, Academic Department of Medicine, Royal Free Hospital, Pond Street, London NW3 2QG, England. 